JGG 2020;68:40-46

doi: 10.36150/2499-6564-351

\title{
The contributions of physical activity and fitness for the optimal health and wellness of the elderly people
}

Israel Oluwasegun Ayenigbara

Department of Health Education, School and Community Health Unit, University of Ibadan, Nigeria

Elderly people often have typical age-related changes that may influence their way of life, for instance; hearing loss, impaired vision, joint pain, hypertension, coronary disease, diabetes, osteoporosis, cognitive impairment and so on. Being physically active helps one with coping better in older years. This review discusses the contribution of physical activity and fitness for the optimal health and wellness of older people. The types of physical activity are discussed, the benefits of physical activities are highlighted and the role of physical activity in the prevention of falls is also reviewed. Specifications for physical activity for the elderly people are highlighted, and importantly, safety considerations for physical activity for the elderly people are provided. In conclusion, physical activities have advantages for the prevention and manage-

Received: July 5, 2019

Accepted: July 22, 2019

\section{Correspondence}

Israel Oluwasegun Ayenigbara

Department of Health Education, School and Community Health Unit, University of Ibadan, Nigeria

Tel. 08139177538

E-mail: histrealite2647@gmail.com

\section{Funding}

The work was self funded by the researcher

\section{Conflict of interest}

The Author declares no conflict of interest

How to cite this article: Ayenigbara $I O$. The contributions of physical activity and fitness for the optimal health and wellness of the elderly people. Journal of Gerontology and Geriatrics 2020;68:40-6. https://doi.org/10.36150/2499-6564-351

(C) Copyright by Società Italiana di Gerontologia e Geriatria (SIGG)

\section{(c) (i) $(9)$}

\section{OPEN ACCESS}

This is an open access article distributed in accordance with the CC-BY-NC-ND (Creative Commons Attribution-NonCommercial-NoDerivatives 4.0 International) license. The article can be used by giving appropriate credit and mentioning the license, but only for non-commercial purposes and only in the original version. For further information: https://creativecommons.org/licenses/by-nc-nd/4.0/deed.en ment of many health-related conditions faced by an elderly person; as such, even limited or moderate physical activity is better than none.

Key words: preventive care, exercise, falls, cardiovascular disease, optimal health

\section{INTRODUCTION}

Most elderly people have age-related changes that may influence their way of life, for example; hearing loss, impaired vision, joint pain, hypertension, coronary disease, diabetes, osteoporosis, cognitive impairment and so on; being physically active helps with coping better in older years ${ }^{1}$.

Physical activity is characterized as any substantial activity which makes use of the skeletal muscles that require energy use ${ }^{2}$. Physical activity incorporates all exercise performed during the 24 hour period, both formal exercise and day to day activities ${ }^{3}$. This activity need not be organized, tedious or planned to get health benefits, and may incorporate activities, for example, strolling to the nearby shop, cleaning, working, walking, and so on. In elderly people of 65 years or more, examples of physical activity include; strolling, planting, climbing, swimming; transportation (e.g. strolling or cycling), family errands, playing, diversions, sports or arranged exercise ${ }^{4}$. Importantly, physical activity is essential for an adult's health because it improves muscle quality, and good muscle tone gives an elderly person the ability to do daily activities around the home. Also, physical activity diminishes the rate of falls and enhances posture. The more time one spends exercising, the more the advantages, as such, any degree of physical activity is better than none ${ }^{1}$. Hence, this review examines the role and importance of physical activities in the prevention 
of non-communicable diseases and falls for the overall improvement of health of elderly people.

\section{METHODS OF REVIEW}

This review focuses on the benefits of physical activity and fitness for the optimal health and wellness of the elderly people. An extensive literature review was performed in Google, Springer link and PubMed data bases. Publications from major international health institutions, such as the World Health Organization, were also searched to retrieve relevant information. The year of publication was not a factor, as the author wished to include all relevant information. Careful screening was done to ensure that pertinent data were included in this review. Subsequently, all references of all studies included in this review were carefully examined.

\section{TYPES OF PHYSICAL ACTIVITY}

There are four basic types of physical activity. They are; Aerobic, Resistance or Muscle-strengthening, BoneStrengthening and Stretching. Elderly people will get the most advantages from physical activity by taking an interest in every one of the four types. For the best health results, it is essential that older people participate in new methods of physical activity every week ${ }^{5}$ (Fig. 1).

1 Aerobic activities. Oxygen consuming (or cardiovascular perseverance) exercises require consistent use of big muscles in the body for 10 minutes. Lively strolling, moving, running, bicycling, dancing, jumping and swimming are good examples. Vigorous activity enhances cardiorespiratory rate, blood pressure and blood lipid reduction. Also, vigorous physical activity enhances physical and mental health ${ }^{6}$.

2 Muscle-strengthening or resistance activities. Resistance activities or muscle-strengthening exercises include making use of resistance activities or exercises to help build muscle mass in the body, and to increase muscle quality. Weight training, digging in the garden and climbing stairs are examples of muscle-strengthening exercises. When combined with bone-strengthening activities, these exercises lessen falls and helps in the optimal functioning for daily activities. Furthermore, bonestrengthening activity enhances portability, lessens falls, enhances step steadiness, diminishes the occurrence of joint inflammation, and prevents osteoporotic cracks in elderly people ?

3 Bone-strengthening activities. Bone-strengthening activities help in the balancing of the body. They are

\begin{tabular}{|c|c|c|c|c|}
\hline $\begin{array}{l}\text { AEROBIC } \\
\text { "Gardening } \\
\text { *Walking } \\
\text {-Dancing } \\
\text { "Swimming } \\
\text { "Jogging } \\
\text { "Water aerobics } \\
\text { "Bicycle riding } \\
\text { (Stationary or on } \\
\text { a path) } \\
\text { "Tennis } \\
\text { "Canocing } \\
\text { "Volleyball } \\
\text { "Hiking uphill } \\
\text { "Washing and } \\
\text { waxing a car } \\
\text { "Washing } \\
\text { windows or } \\
\text { floors }\end{array}$ & $\begin{array}{l}\text { RESISTANCE } \\
\text { "Weight } \\
\text { machines } \\
\text { "Hand-held } \\
\text { weights } \\
\text { "Callisthenic } \\
\text { exereise } \\
\text { "Digging } \\
\text { "Lifting } \\
\text { "Carrying } \\
\text { groceries } \\
\text { "Shoveling } \\
\text {-Push-ups } \\
\text { "Sit-ups } \\
\text {-Pilates } \\
\text { "Climbing stairs }\end{array}$ & $\begin{array}{l}\text { BALANCE } \\
\text { "Backward } \\
\text { walking } \\
\text { "Sideways } \\
\text { walking } \\
\text { "Heel walking } \\
\text { *Toe walking } \\
\text { "Standing from a } \\
\text { sitting position } \\
\text { "Heel walking } \\
\text { "Mopping } \\
\text { vacuuming } \\
\text {-Yoga } \\
\text { "Modified tai chi }\end{array}$ & $\begin{array}{l}\text { STRETCHING } \\
\text { "Neck stretch } \\
\text { "Chest stretch } \\
\text { "Ankle stretch } \\
\text { "Hamstring } \\
\text { stretch } \\
\text { *Quadriceps } \\
\text { stretch } \\
\text { *Hip stretch } \\
\text { "Lower back } \\
\text { stretch } \\
\text { *Shoulder stretch } \\
\text { "Hand stretch } \\
\text { "Ankle stretch }\end{array}$ & $\begin{array}{c}\underset{\text { MORE }}{\downarrow} \\
\text { Vigorous } \\
\text { Less time }\end{array}$ \\
\hline $\begin{array}{l}\text { * It is importa } \\
\text { flexibility acti } \\
\text { back, it is imp } \\
\text { flexibility exe }\end{array}$ & $\begin{array}{l}\text { t to talk to } \\
\text {, especially, }\end{array}$ & lower-back r & $\begin{array}{l}\text { der before e } \\
\text { n. }\end{array}$ & $\begin{array}{l}\text { specially } \\
\text { e hip or } \\
\text { g in any }\end{array}$ \\
\hline
\end{tabular}

Figure 1. Examples of activities guide for the elderly people. Self developed.

basic exercises that can be performed in the home, for example, remaining on one leg unsupported, jumping with a rope, walking and lifting weights. Importantly, improvement in balancing diminishes the risk of falls, and enhances mobility ${ }^{8}$. Tai chi significantly enhances balance and decrease falls in elderly people ${ }^{9}$.

4 Stretching activities. Stretching activities improves flexibility, and the ability to move the joints. Body flexibility reduces as one ages ${ }^{10}$. Stretching activities includes touching of toes, doing side stretches. Also, yoga is another example of stretching activities, washing of dishes and family home chores, (for example, sweeping, washing and planting) are examples of flexibility exercises as well ${ }^{11}$.

\section{BENEFITS OF PHYSICAL ACTIVITY TO THE HEALTH OF AN ELDERLY PERSON}

The advantages of physical activity to the health of elderly people are entrenched and numerous ${ }^{12}$. Notably, physical activity has considerable advantages for the prevention and management of certain health-related conditions, and improvement of the overall health and personal satisfaction in elderly people. For example, a study revealed that the multifactorial, interdisciplinary primary healthcare intervention focused on physical exercise helps in the prevention of frailty in pre-frail 
elderly patients, and improves functional capacity, quality of life and adherence to the Mediterranean diet $^{13}$. Also, resistance activities are effective to reduce blood pressure (peripheral and central) in middle-aged and older adults with at least elevated blood pressure at baseline ${ }^{14}$. In addition, a study 'Exercise Intervention on Functional Decline in Very Elderly Patients during Acute Hospitalization' revealed that the exercise intervention proved to be safe and effective to reverse the functional decline associated with acute hospitalization in elderly patients ${ }^{15}$. Furthermore, physical activity helps in the prevention of cardiovascular diseases which are associated with death, like chronic ischaemic heart disease, pulmonary heart disease, arrhythmias, heart failure, cerebrovascular events, aneurysm and peripheral vascular diseases ${ }^{16}$. Even low doses of physical activity are protective for health and reduce by $22 \%$ the risk of premature death ${ }^{17}$. Furthermore, physical activity is an important therapeutic tool for patients with cardiovascular diseases, hypertension, type 2 diabetes, cancer, chronic obstructive pulmonary disease (COPD), as an appropriate dosage of physical activity reduces the risk of recurrence and disease progression, improves the control of clinical parameters and increases the quality of life ${ }^{17}$. People with COPD may benefit from engagement in low levels of physical activity, particularly walking and structured exercise ${ }^{18}$. Exercise training may be an effective strategy to promote metabolic health, and also increase brainderived neurotrophic factor (BDNF); a protein favoring neuroplasticity, thereby helping in learning and memory improvements in an elderly people, and also improvements in diabetes risk factors ${ }^{19}$. Likewise, preconditioning exercise reduces brain damage and neuronal apoptosis ${ }^{20}$. Furthermore, bone fractures and breakage risk can be prevented and reduced among elderly women through engagement in physical activity and reduction in sedentary lifestyle ${ }^{21}$. There is an association between physical activity and reduced risk of depression, as elderly people engaging in physical activity can reduce their risk of depression and anxiety ${ }^{22,}$ ${ }^{23}$. Further evidence of benefit is provided by the doseresponse relationship; high-intensity physical activity has more obvious cardiovascular benefits than those of moderate-intensity physical activity ${ }^{24}$. A study on the effect of 6 months of aerobic training on adipokines as breast cancer risk factors in postmenopausal women revealed that exercise programs can be considered as an effective behavioral modification in breast cancer prevention ${ }^{25}$. Also, for improved functional ability in elderly people with dementia, a person-centered exercise approach, delivered by an expert is effective ${ }^{26}$.

\section{THE ROLE OF PHYSICAL ACTIVITY IN THE PREVENTION OF FALLS}

Falls are common in older people aged 65 years and above, and are the main causes of injuries in this age group; as around $33 \%$ of elderly individuals of more than 65 years fall every year, and half of those in their eighties fall once per year ${ }^{27,28}$. It is estimated that $82 \%$ of hospital admissions for adults over 75 years are falls-related, and falls frequently happen while an elderly individual is doing common activities in the home ${ }^{28,29}$. The rate of falls increases drastically with age ${ }^{28,29}$. Importantly, most falls are preventable, and physical activity has a vital role in lessening the danger and rate of falls in elderly people. A multifaceted intervention which includes exercise reduces the rate of falls in elderly people ${ }^{30}$. A study on the Interventions to Prevent Falls in Older Adults revealed that exercise is associated with fewer people experiencing a fall and a reduced number of injurious falls in averageand high-risk older adults ${ }^{31}$. Furthermore, a multifactorial tailored approach (which included physical exercise) for treating dizziness (a risk factor for falls in elderly people) was effective in reducing dizziness handicap in community-living people aged 50 years and older ${ }^{32}$. Exercise decreases the risk of falls among elderly people with Alzheimer's disease using antihypertensive and psychotropic drugs ${ }^{33}$. Furthermore, a study on the effect of Exercise and Cognitive Training on fall and Fall-Related Factors in Older Adults with Mild Cognitive Impairment revealed that, exercise, and combined exercise and cognitive training improve specific factors associated with falls such as gait speed, cognitive function, and balance in adults with mild cognitive impairment ${ }^{34}$. Also, exercise as a single intervention prevents falls in community-dwelling elderly people; therefore, an exercise programme that improves balance, and are of a higher dose have larger effects on the prevention of falls ${ }^{35}$. In addition, Lafiska, a form of exercise in Indonesia, improves balance and health status in the elderly people, and is a viable exercise option in the prevention of falls in older adults with independent mobility, as well as older adults using assistive devices, for example, a walking stick ${ }^{36}$. Also, a study on the effects of Tai Chi Chuan, a form of exercise originating in Asia and 'Brisk Walking Exercise on Balance Ability in Elderly Women' revealed that 12 and 16 weeks of Tai Chi Chuan and brisk walking respectively were essential to improve balance (which is a major factor in risk of fall) with eyes closed among the women aged 60-70 years. Exercise can either be done alone or in groups, although, group exercise is the best as older adults who participate in group exercise receives additional benefits related to falls prevention compared with those who exercise alone ${ }^{37,38}$. 


\section{SPECIFICATIONS FOR PHYSICAL ACTIVITY IN THE ELDERLY PEOPLE}

As indicated by the World health organization ${ }^{4}$ :

- elderly people and adults should do 150 minutes of aerobic physical activity consistently, or do no less than 75 minutes of vigorous-intensity aerobic physical activity consistently, or a proportionate mixture of moderate- and vigorous-intensity activity;

- aerobic activity should be performed for 10 minutes;

- for extra medical advantages, elderly people should expand their moderate-intensity aerobic physical activity to 300 minutes every week, or participate in 150 minutes of vigorous-intensity aerobic physical activity every week, or a proportionate mixture of moderate-and vigorous- intensity activity;

- elderly individuals with poor mobility should perform physical activity to improve balance and avert falls in at least three days of the week;

- muscle-strengthening exercises, which include the use of significant muscles in the body, should be done on at least two days in the week;

- at the point when elderly people cannot do the prescribed measures of physical activity because of health conditions, they should be as physically active as their abilities and health conditions permit.

\section{SAFETY CONSIDERATIONS IN PHYSICAL ACTIVITY FOR THE ELDERLY PEOPLE}

There are risks related to elderly people taking part in significant numbers of physical activities, because not all physical activities can be performed safely by an elderly person. Proper screening and ongoing management by a health professional or physical activity specialist is required for high-effect and serious exercises to guarantee that an elderly person stays safe. In spite of the advantages of physical activity, physical activity may disturb and aggravate some prior health conditions, for example, angina, joint inflammation, osteoporosis, extreme hypertension and previous wounds 39,40 . To prevent a health condition from being aggravated while an elderly person is partaking in a specific activity, a reasonable degree of physical activity can be performed with endorsement from the individual's general practitioner (GP), physiotherapist or clinical exercise physiologist. If an elderly person has persistent illnesses, geriatric conditions or disability, or has been inactive for a long time, the person needs to be checked by their GP, physiotherapist or clinical exercise physiologist before one can attempt an activity program or strenuous physical activity (Fig. 2).
Although, it is safe for elderly individuals with comorbidities or disability to take part in physical activity, it is best to begin with lower-intensity activities and progressively advance onto moderate or higher-impact activities. Furthermore, elderly people should stop physical activity if their breathing becomes difficult or if they feel woozy or develop any chest tightness or pain. Also, elderly individuals with disability should defer high impact or weight-bearing aerobic exercises until the point when they have undertaken sufficient balance and strength training. A straightforward test to check whether an elderly individual is ready to undertake moderate-intensity aerobic or higher-impact activities exercises is to get the individual to get up from a seat, remain with their eyes closed, open one eye, and afterward stroll across the room ${ }^{12}$. If the elderly person experiences issues with this activity, they need to work on resistance and balance training before attempting aerobic or higher-impact exercises.

\section{CONCLUSIONS}

The importance of Physical activity are many as it diminishes the risk of various non-communicable and chronic health conditions, which includes heart disease, hypertension, type 2 diabetes, colon, post-menopausal breast and endometrial cancers, stroke, osteoporosis, osteoarthritis, depression, falls and disability in the elderly people 12,14,16,17,19,21-24,26,30-38. From the extant review, it is therefore concluded that physical activities have numerous advantages for the prevention and management of many health-related conditions been faced by the elderly people. Hence, it is imperative for every elderly person to always engage in physical activities to obtain optimal health and wellbeing in their old age, as limited or moderate physical activity is better for health and wellness of older people than none. Furthermore, it is important for elderly people to always talk to their health care provider if they have any prior health condition or they feel unease before, during and after any physical activity sessions to guaranty health safety.

\section{ACKNOWLEDGEMENTS}

Great thanks are given to unknown reviewers for valuable comments. Furthermore, I thank all my colleagues who over the time have contributed to the ideas discussed in this article.

\section{Dedication}

The article is dedicated to all the elderly people around the world. 


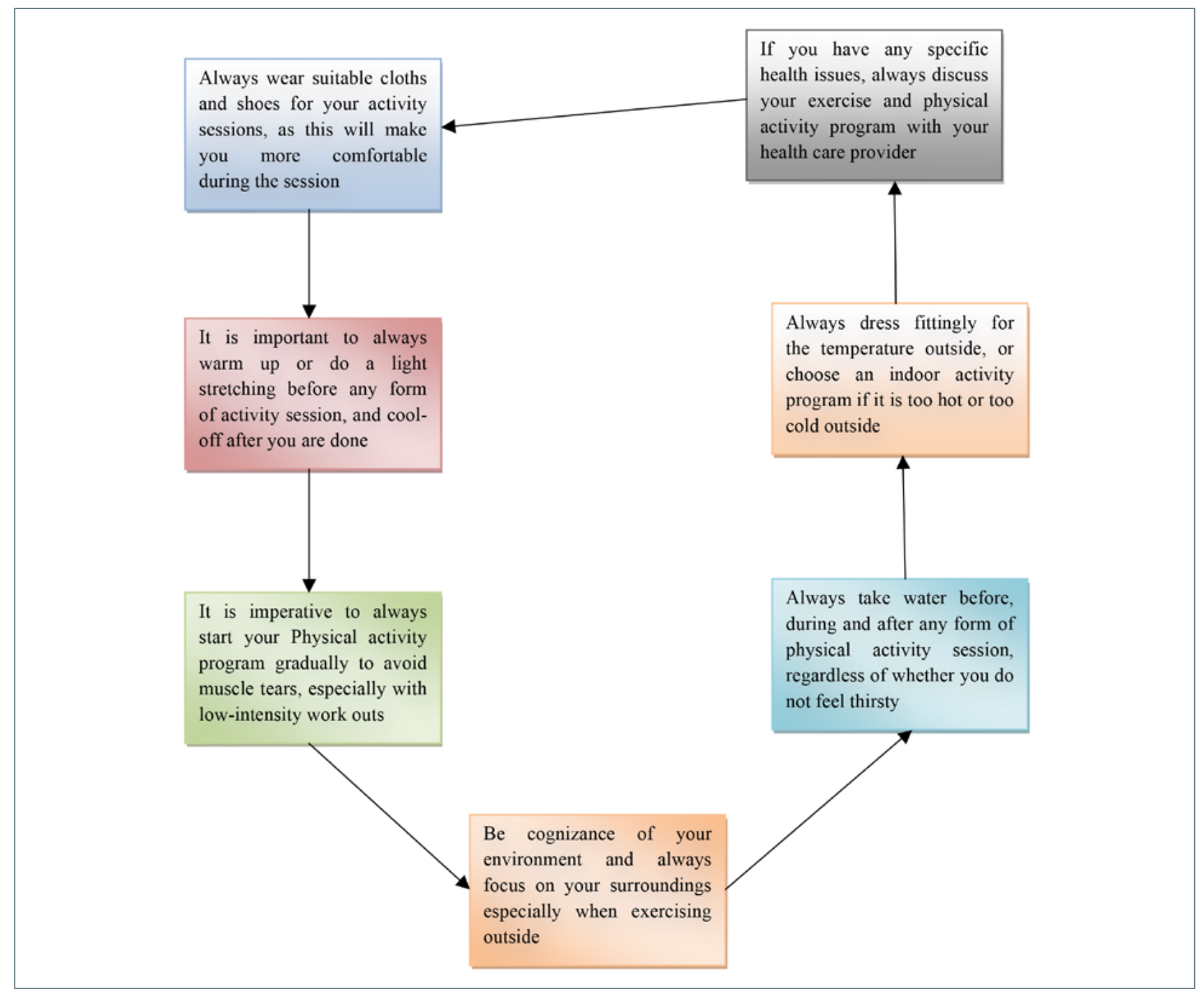

Figure 2. How to stay safe and reduce the risk of injury during physical activity sessions. Self developed.

\section{References}

1 Novus Care. Importance of physical activity for older adults living at home. 2017 (https://www.novus-care.com/latestnews/importance-of-physical-activity-for-older-adultsliving-at-home) (retrieved September 14, 2018).

2 World Health Organization. Global Recommendations on Physical Activity for Health. Geneva, Switzerland: 2009 (https://www.who.int/ncds/prevention/physical-activity/ en) (retrieved September 14, 2018).

3 Page A, Peeters G, Merom D. Adjustment for physical activity in studies of sedentary behaviour. Emerg Themes Epidemiol 2015;12. https://doi.org/10.1186/s12982-0150032-9

4 World Health Organization. Physical activity and older adult. 2018 (http://www.who.int/dietphysicalactivity/ factsheet_olderadults/en) (retrieved September 14, 2018).

5 Netwellness. Types of physical activity. 2017 (http://www. netwellness.org/healthtopics/healthyweight/typeactivity. cfm) (retrieved October 8, 2018).

6 Coutaz M. Prevention in older age: key factors. Rev Med Suisse 2018;14:1998-2002.

7 Vikberg S, Sörlén N, Brandén L, et al. Effects of resistance training on functional strength and muscle mass in70year-old individuals with pre-sarcopenia: a randomized controlled trial. J Am Med Dir Assoc 2018;(18):30502-4. https://doi.org/10.1016/j.jamda.2018.09.011

8 Steadman J, Donaldson N, Kalra L. A randomized controlled trial of an enhanced balance training program to improve mobility and reduce falls in elderly patients. J Am Geriatr Soc 2003;51:847-52. https://doi.org/10.1046/ j.1365-2389.2003.51268.x

$9 \mathrm{Li} \mathrm{F}$, Harmer P, Fisher KJ, et al. Tai Chi and fall reductions in older adults: a randomized controlled trial. J Gerontol Biol Sci Med Sci 2006;60:187-94. 
10 Laukkanen P, Era P, Heikkinen RL, et al. Factors related to carrying out everyday activities among elderly people aged 80. Aging Clin Exp Res 1994;6: 433-43. https://doi. org/10.1007/BF03324275

11 Chen L, Wang S, Xu JC. Survey on physical fitness and cardiovascular function of the city elderly in different regular physical activities in China. J Nutr Health Aging 2018;22:1107-11. https://doi.org/10.1007/s12603-0181070-0

12 Turner JE, Lira VA, Brum PC. New insights into the benefits of physical activity and exercise for aging and chronic disease. Oxid Med Cell Longev 2017;2503767. https:// doi.org/10.1155/2017/2503767

13 Gené-Huguet L, Navarro-González M, Kostov B, et al. Pre frail 80: multi factorial intervention to prevent progression of pre-frailty to frailty in the elderly. $J$ Nutr Health Aging 2018;22:1266-74. https://doi.org/10.1007/s12603-0181089-2

14 Figueroa A, Okamoto T, Jaime SJ, et al. Impact of highand low-intensity resistance training on arterial stiffness and blood pressure in adults across the lifespan: a review. Pflugers Arch 2018. https://doi.org/10.1007/s00424-0182235-8

15 Martínez-Velilla N, Casas-Herrero A, Zambom-Ferraresi F, et al. Effect of exercise intervention on functional decline in very elderly patients during acute hospitalization: a randomized clinical trial. JAMA Intern Med 2018. https:// doi.org/10.1001/jamainternmed.2018.4869

16 Hamer M, O'Donovan G, Stamatakis E. Association between physical activity and sub-types of cardiovascular disease death causes in a general population cohort. Eur J Epidemiol 2018. https://doi.org/10.1007/s10654-0180460-2

17 Capodaglio EM. Physical activity, tool for the prevention and management of chronic diseases. G Ital Med LavErgon 2018;40:106-19.

18 Cheng SWM, McKeough, Z, Alison J, et al. Associations of total and type-specific physical activity with mortality in chronic obstructive pulmonary disease: a populationbased cohort study. BMC Public Health 2018;18:268. https://doi.org/10.1186/s12889-018-5167-5

19 Walsh JJ, D'Angiulli A, Cameron JD, et al. Changes in the brain-derived neurotrophic factor are associated with improvements in diabetes risk factors after exercise training in adolescents with obesity: the HEARTY randomized controlled trial. Neural Plast 2018;7169583. https://doi. org/10.1155/2018/7169583

20 Otsuka S, Sakakima H, Terashi T, et al. Preconditioning exercise reduces brain damage and neuronal apoptosis through enhanced endogenous 14-3-3 $\gamma$ after focal brain ischemia in rats. Brain Struct Funct 2018.https://doi. org/10.1007/s00429-018-1800-4

21 Rodríguez-Gómez I, Mañas A, Losa-Reyna J, et al. Associations between sedentary time, physical activity and bone health among older people using compositional data analysis. PLoS One 2018;13:e0206013. https://doi. org/10.1371/journal.pone.0206013
22 Yasunaga A, Shibata A, Ishii $K$, et al. Cross-sectional associations of sedentary behaviour and physical activity on depression in Japanese older adults: an isotemporal substitution approach. BMJ Open 2018;8:e022282. https://doi.org/10.1136/bmjopen-2018-022282

23 McDowell CP, Dishman RK, Hallgren M, et al. Associations of physical activity and depression: results from the Irish longitudinal study on ageing. Exp Gerontol 2018;112:6875. https://doi.org/10.1016/j.exger.2018.09.004

24 Cheng W, Zhang Z, Cheng W, et al. Associations of leisure-time physical activity with cardiovascular mortality: a systematic review and meta-analysis of 44 prospective cohort studies. Eur J Prev Cardiol 2018;25:1864-72. https://doi.org/10.1177/2047487318795194

25 Khosravi N, Eskandari Z, Farajivafa V, et al. Effect of 6 months of aerobic training on adipokines as breast cancer risk factors in postmenopausal women: a randomized controlled trial. J Cancer Res Ther 2018;(6):1336-40. https://doi.org/10.4103/jcrt.JCRT_684_16

26 Post D, Corlis M, Penington A, et al. Exercise physiology in aged care: perceptions and acceptability from the perspectives of family members and care staff in the residential aged care environment. Dementia (London) 2018;1471301218816246. https://doi. org/10.1177/1471301218816246

27 Frieson CW, Tan MP, Ory MG, et al. Editorial: evidencebased practices to reduce falls and fall-related injuries among older adults. Front Public Health 2018;6:222. https://doi.org/10.3389/fpubh.2018.00222

28 Accident Compensation Corporation. Preventing injuries: trips and falls, 2017 (https://www.acc.co.nz/preventinginjury/trips-falls) (retrieved September 3, 2018).

29 Pereira CLN, Vogelaere P, Baptista F. Academic literature review: role of physical activity in the prevention of falls and their consequences in the elderly. Eur Rev Aging Phys Act 2008;5:51-8. https://doi.org/10.1007/s11556-008-00318

30 Hopewell S, Adedire O, Copsey BJ, et al. Multifactorial and multiple component interventions for preventing falls in older people living in the community. Cochrane Database Syst Rev 2018;7:CD012221. https://doi. org/10.1002/14651858.CD012221.pub2

31 Guirguis-Blake JM, Michael YL, Perdue LA, et al. Interventions to prevent falls in older adults: updated evidence report and systematic review for the US Preventive Services Task Force. JAMA 2018;319:1705-16. https://doi.org/10.1001/jama.2017.21962

32 Menant JC, Migliaccio AA, Sturnieks DL, et al. Reducing the burden of dizziness in middle-aged and older people: a multifactorial, tailored, single-blind randomized controlled trial. PLoS Med 2018;15:e1002620. https://doi. org/10.1371/journal.pmed.1002620

33 Perttila NM, Öhman H, Strandberg TE, et al. Effect of exercise on drug-related falls among persons with Alzheimer's disease: a secondary analysis of the FINALEX study. Drugs Aging 2018;35:1017-23. https://doi. org/10.1007/s40266-018-0594-7 
34 Lipardo DS, Aseron AMC, Kwan MM, et al. Effect of exercise and cognitive training on fall and fall-related factors in older adults with mild cognitive impairment: a systematic review. Arch Phys Med Rehabil 2017;98:207996. https://doi.org/10.1016/j.apmr.2017.04.021

35 Sherrington C,Michaleff ZA, Fairhall N, et al. Exercise to prevent falls in older adults: an updated systematic review and meta-analysis. Br J Sports Med 2017;51:1750-8. https://doi.org/10.1136/bjsports-2016-096547

36 Kusuma-Wati DN, Sahar J, Rekawati E. Effectiveness of Lafiska exercise on risk of fall, balance, and health status in the elderly. EnfermClin 2018;(Suppl 1):337-42. https://doi. org/10.1016/S1130-8621(18)30181-5

37 Sun W, Ma X, Wang L, et al. Effects of Tai Chi Chuan and Brisk walking exercise on balance ability in elderly women: a randomized controlled trial. Motor Control 2018;15:1-15. https://doi.org/10.1123/mc.2017-0055

38 Hayashi T, Kondo K, Kanamori S, et al. Differences in falls between older adult participants in group exercise and those who exercise alone: a cross-sectional study using Japan Gerontological Evaluation Study (JAGES) Data. Int J Environ Res Public Health 2018;15. pii: E1413. https://doi. org/10.3390/ijerph15071413

39 Mazzeo RS, Tanaka H. Exercise prescription for the elderly: current recommendations. Sports Medicine 2001;31:80918. https://doi.org/10.2165/00007256-200131110-00003

40 Mendonca GV, Pezarat-Correia P, Vaz JR, et al. Impact of exercise training on physiological measures of physical fitness in the elderly. Curr Aging Sci 2016;9:240-59. https://doi.org/10.2174/1874609809666160426120600 